\title{
The Right Heart-Pulmonary Circulation Unit and Left Heart Valve Disease
}

\author{
Laura Filippetti, MDª, Damien Voilliot, MD ${ }^{a, b}$, \\ Michele Bellino, $\mathrm{MD}^{\mathrm{C}}$, Rodolfo Citro, $\mathrm{MD}, \mathrm{PhD}^{\mathrm{C}}$, \\ Yun Yun Go, MD ${ }^{d, e}$, Patrizio Lancellotti, MD, PhD ${ }^{e, f, g, *}$
}

\section{KEYWORDS}

- Valvular heart disease • Echocardiography • Exercise $\bullet$ Pulmonary hypertension • Outcome

\section{KEY POINTS}

- Pulmonary hypertension $(\mathrm{PH})$ is a classical pathophysiologic consequence of left-sided valvular heart disease (VHD). Aortic and mitral valve (stenosis and regurgitation) diseases are frequently accompanied by $\mathrm{PH}$, especially when they are severe and symptomatic.

- In asymptomatic patients, $\mathrm{PH}$ is rare, although the exact prevalence is unknown and mainly stems from the severity of the VHD and the presence of diastolic dysfunction. Recently, exercise echocardiography has gained interest in depicting $\mathrm{PH}$.

- In these asymptomatic patients, exercise PH is observed in about greater than $40 \%$. Either $\mathrm{PH}$ at rest or during exercise is also a powerful determinant of outcome and is independently associated with reduced survival, regardless of the severity of the underlying valvular pathology.

- $\mathrm{PH}$ is a marker of poor prognosis; assessment of PH in VHD is crucial for risk stratification and management of patients with VHD.

\section{INTRODUCTION}

Pulmonary hypertension $(\mathrm{PH})$ described in valvular heart disease (VHD) is frequent and belongs to the group 2 corresponding to $\mathrm{PH}$ related to left heart disease according to the new classification of $\mathrm{PH} .{ }^{1}$ Diagnosis of $\mathrm{PH}$ related to VHD is based on the following criteria: mean pulmonary arterial pressure (PAP) greater than $25 \mathrm{~mm} \mathrm{Hg}$ associated with pulmonary capillary wedge pressure (PCWP) or left ventricular (LV) end-diastolic pressure greater than $15 \mathrm{~mm} \mathrm{Hg}$. The increase of LV volume or pressure in VHD induces a rise of left atrial (LA) pressure, which causes a passive backward transmission to the pulmonary venous system with subsequent increase of $\mathrm{PH} .{ }^{2}$ Persistent high pulmonary venous pressure can induce irreversible vasculature vasoconstriction and hyperplasia

Conflict of Interest: None.

Financial Disclosure: None.

a Department of Cardiology, University Hospital of Nancy, Lorrain Institute for Heart and Vessels, F-54500 Vandoeuvre-lès-Nancy, France; b IADI Laboratory (DIAGNOSIS AND INTERVENTIONAL ADAPTIVE IMAGING), INSERM U947, University of Lorraine, F-54500 Nancy, France; ${ }^{c}$ Department of Cardiology, University Hospital "San Giovanni di Dio e Ruggi d'Aragona", Largo Città di Ippocrate, 84131 Salerno, Italy; " National Heart Research Institute Singapore, National Heart Centre Singapore, 5 Hospital Drive, 16960 Singapore, Singapore; e GIGA Cardiovascular Sciences, University Hospital Sart Tilman, 4000 Liège, Belgium; ${ }^{f}$ Heart Valve Clinic, Department of Cardiology, University Hospital Sart Tilman, 4000 Liège, Belgium; 9 Gruppo Villa Maria Care and Research, Anthea Hospital, VIA C. ROSALBA, 35/37 70124 Bari, Italy

* Corresponding author. Department of Cardiology, Domaine Universitaire du Sart Tilman, University Hospital, Université de Liège, CHU du Sart Tilman, Batiment B35, Liège 4000, Belgium.

E-mail address: plancellotti@chu.ulg.ac.be 
contributing to further increase in $\mathrm{PH}$, excessive regarding $\mathrm{PCWP}^{3}$ At advanced stage of $\mathrm{VHD}$, chronic PH contributes to increased right ventricular (RV) afterload and leads to progressive RV remodeling, including $\mathrm{RV}$ hypertrophy followed by $\mathrm{RV}$ dilatation. It leads to increased tricuspid regurgitation (TR) severity and RV dysfunction. When PH occurs in VHD, it is frequently associated with clinical symptoms (Fig. 1).

Echocardiography gives an estimation of systolic PAP (sPAP) and plays a key role in assessment of VHD and consequences of $\mathrm{PH}$, in particular on RV function (Table 1). In some cases, right heart catheterization is mandatory to determine accurate value of PCWP and confirm diagnosis. Many indices have been developed for quantifying RV function, but reference standards for RV functional assessment are lacking. 4,5 The development of threedimensional echocardiography and cardiac magnetic resonance provides a better evaluation of RV volume and geometry than conventional two-dimensional echocardiography. 2,6

Because $\mathrm{PH}$ is a marker of poor prognosis, assessment of $\mathrm{PH}$ in VHD is crucial for risk stratification and management of patients (Table 2). The impact of RV function on outcomes of VHD has been underestimated for a long time, ${ }^{7}$ whereas it is now clearly established that RV failure compromises patient outcomes in VHD. ${ }^{2,8}$

\section{RESTING PULMONARY HYPERTENSION AND AORTIC STENOSIS}

Prevalence of resting $\mathrm{PH}$ in aortic stenosis (AS) is difficult to establish because it depends on clinical profile and definition of $\mathrm{PH}$. Lancellotti and colleagues ${ }^{9}$ reported only $6 \%$ of resting $\mathrm{PH}$ in a series of 105 patients presenting with asymptomatic AS, whereas the prevalence of $\mathrm{PH}$ could range from

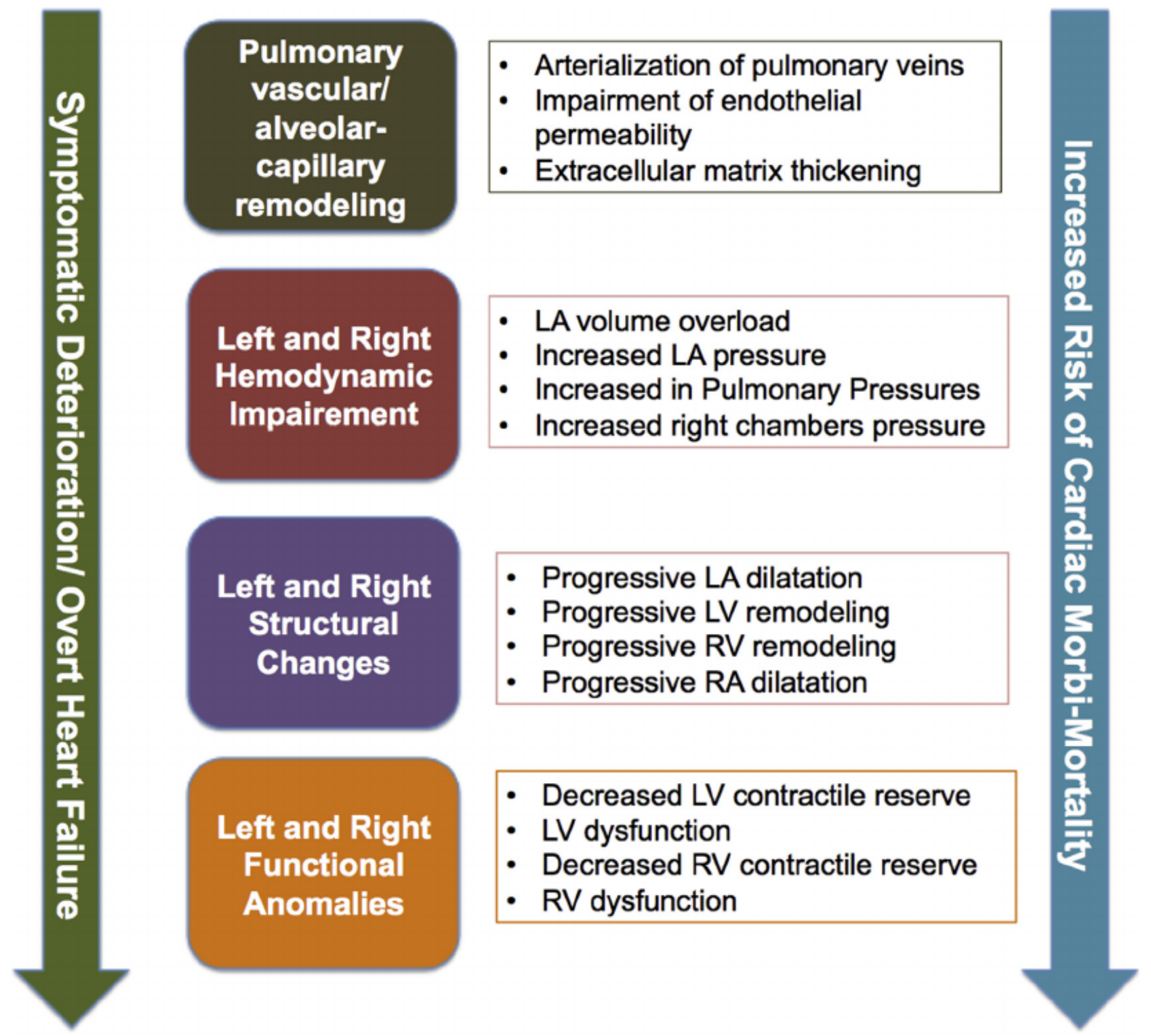

Fig. 1. Hemodynamic, structural, and functional changes induced by left-sided valvular. 
Table 1

Echocardiographic features used for diagnosing pulmonary hypertension

\begin{tabular}{|c|c|c|c|c|c|}
\hline $\begin{array}{l}\text { Peak TR Velocity } \\
\text { (sPAP) }\end{array}$ & Inferior VC & $\begin{array}{l}\text { RV vs LV } \\
\text { RA Area } \\
\end{array}$ & Septal Wall & $\begin{array}{l}\text { Pulmonary } \\
\text { AT }\end{array}$ & $\begin{array}{l}\text { Likelihood } \\
\text { of } \mathrm{PH} \\
\end{array}$ \\
\hline $\begin{array}{l}\leq 2.8 \mathrm{~m} / \mathrm{s} \\
\quad(\leq 36 \mathrm{~mm} \mathrm{Hg})\end{array}$ & $\begin{array}{l}\leq 2.1 \mathrm{~cm} \\
\text { Inspiratory } \\
\quad \text { collapse }>50 \% \\
\end{array}$ & $\begin{array}{l}\mathrm{RV}<\mathrm{LV} \\
\mathrm{RA} \text { area }<18 \mathrm{~cm}^{2}\end{array}$ & Normal & $>105 \mathrm{~ms}$ & Unlikely/low \\
\hline $\begin{array}{l}\leq 2.8 \mathrm{~m} / \mathrm{s} \\
\quad(\leq 36 \mathrm{~mm} \mathrm{Hg})\end{array}$ & $\begin{array}{l}>2.1 \mathrm{~cm} \\
\text { Inspiratory collapse } \\
\quad<50 \%\end{array}$ & $\begin{array}{l}\mathrm{RV} \geq \mathrm{LV} \\
\mathrm{RA} \text { area } \geq 18 \mathrm{~cm}^{2}\end{array}$ & $\begin{array}{l}\text { Flattening } \\
\text { Abnormal } \\
\text { septal } \\
\text { motion }\end{array}$ & $<105 \mathrm{~ms}$ & Intermediate \\
\hline $\begin{array}{l}2.9-3.4 \mathrm{~m} / \mathrm{s} \\
\quad(37-50 \mathrm{~mm} \mathrm{Hg})\end{array}$ & $\begin{array}{l}\leq 2.1 \mathrm{~cm} \\
\text { Inspiratory } \\
\quad \text { collapse }>50 \% \\
\end{array}$ & $\begin{array}{l}\mathrm{RV}<\mathrm{LV} \text { size } \\
\mathrm{RA} \text { area }<18 \mathrm{~cm}^{2}\end{array}$ & Normal & $>105 \mathrm{~ms}$ & \\
\hline $\begin{array}{l}2.9-3.4 \mathrm{~m} / \mathrm{s} \\
(37-50 \mathrm{~mm} \mathrm{Hg})\end{array}$ & $\begin{array}{l}>2.1 \mathrm{~cm} \\
\text { Inspiratory collapse } \\
\quad<50 \%\end{array}$ & $\begin{array}{l}\mathrm{RV} \geq \mathrm{LV} \\
\mathrm{RA} \text { area } \geq 18 \mathrm{~cm}^{2}\end{array}$ & $\begin{array}{l}\text { Flattening } \\
\text { Abnormal } \\
\text { septal } \\
\text { motion }\end{array}$ & $<105 \mathrm{~ms}$ & High \\
\hline $\begin{array}{l}>3.4 \mathrm{~m} / \mathrm{s} \\
\quad(>50 \mathrm{~mm} \mathrm{Hg})\end{array}$ & \multicolumn{5}{|c|}{ Presence or not of supportive signs } \\
\hline
\end{tabular}

Other supportive signs are: pulmonary artery diameter greater than $25 \mathrm{~mm}$, early diastolic pulmonary regurgitation velocity greater than $2.2 \mathrm{~m} / \mathrm{s}$.

Abbreviations: AT, acceleration time; RA, right atrial; sPAP, systolic pulmonary arterial pressure; VC, vena cava.

$47 \%$ to $65 \%$ in patients with symptomatic aortic disease. ${ }^{10,11}$ Roselli and colleagues ${ }^{12}$ found that $74 \%$ of patients with severe AS presented with moderate (sPAP from 35 to $50 \mathrm{~mm} \mathrm{Hg}$ ) to severe (sPAP $>50 \mathrm{~mm} \mathrm{Hg}$ ) PH, as assessed by echocardiography. However, the level and the severity of $\mathrm{PH}$ depends more on diastolic burden that the severity of AS. ${ }^{10,13}$

The presence of $\mathrm{PH}$ is a sign of advanced disease stage. It has been found that moderate to severe $\mathrm{PH}$ was associated with poor prognosis in cases of conservative therapy. ${ }^{14}$ Indeed, several studies identified elevated $\mathrm{PH}$ at baseline as an independent predictive factor for early and late mortality after aortic valve replacement (AVR), whereas patients with normal $\mathrm{PH}$ at baseline presented a good prognosis. ${ }^{15}$ Melby and colleagues ${ }^{11}$ showed that patients with $\mathrm{PH}$ had a higher risk of operative mortality than without $\mathrm{PH}(5.4 \%$ vs $9.3 \% ; P=.02)$. Interestingly, the degree/level of preoperative $\mathrm{PH}$ seemed to be associated with the postoperative survival rates. Roselli and colleagues ${ }^{12}$ demonstrated that patients with severe PH (sPAP $>50 \mathrm{~mm} \mathrm{Hg}$ ) had the worst prognosis (31\% 10-year survival). Barbarsh and colleagues ${ }^{16}$ found similar results in case of transcatheter aortic valve implantation (TAVR): severe $\mathrm{PH}$ at baseline is a predictive factor of mortality at 1 year after performing TAVR in a group of 415 patients with symptomatic AS. It has been demonstrated that $\mathrm{PH}$ may be reversible, at least partially, because remodeling of pulmonary vasculature and may decrease after AVR or TAVR, ${ }^{12}$ in particular in patients with higher preoperative PCWP. ${ }^{14}$ Nevertheless, persistent $\mathrm{PH}$ after procedure is associated with adverse outcomes. ${ }^{11}$

Although preoperative $\mathrm{PH}$ was clearly associated with early and late postoperative morbidity and mortality, actual recommendations consider resting $\mathrm{PH}$ as a trigger for AVR or TAVR. ${ }^{17,18}$ Optimal timing of AVR or TAVR in asymptomatic severe AS remains challenging. ${ }^{2}$ Therefore, $\mathrm{PH}$ is often associated with symptoms and its presence might suggest hidden symptoms in apparently asymptomatic patents, classically in elderly patients with limited activities. ${ }^{19}$ In practice, AVR should be considered in patients with $\mathrm{PH}$ at rest if confirmed by a right heart catheterization and if the risk of intervention is perfectly weighted. ${ }^{17}$

\section{RESTING PULMONARY HYPERTENSION AND PRIMARY/SECONDARY MITRAL REGURGITATION}

Primary and secondary mitral regurgitation (MR) are common causes of resting $\mathrm{PH}$ and its prevalence depends on MR severity, clinical status, and LV systolic function. ${ }^{19}$ Ghoreishi and colleagues ${ }^{20}$ reported significant PH (sPAP $>50 \mathrm{~mm}$ $\mathrm{Hg}$ ) in $20 \%$ to $30 \%$ of patients with severe primary MR and up to $64 \%$ in symptomatic patients 


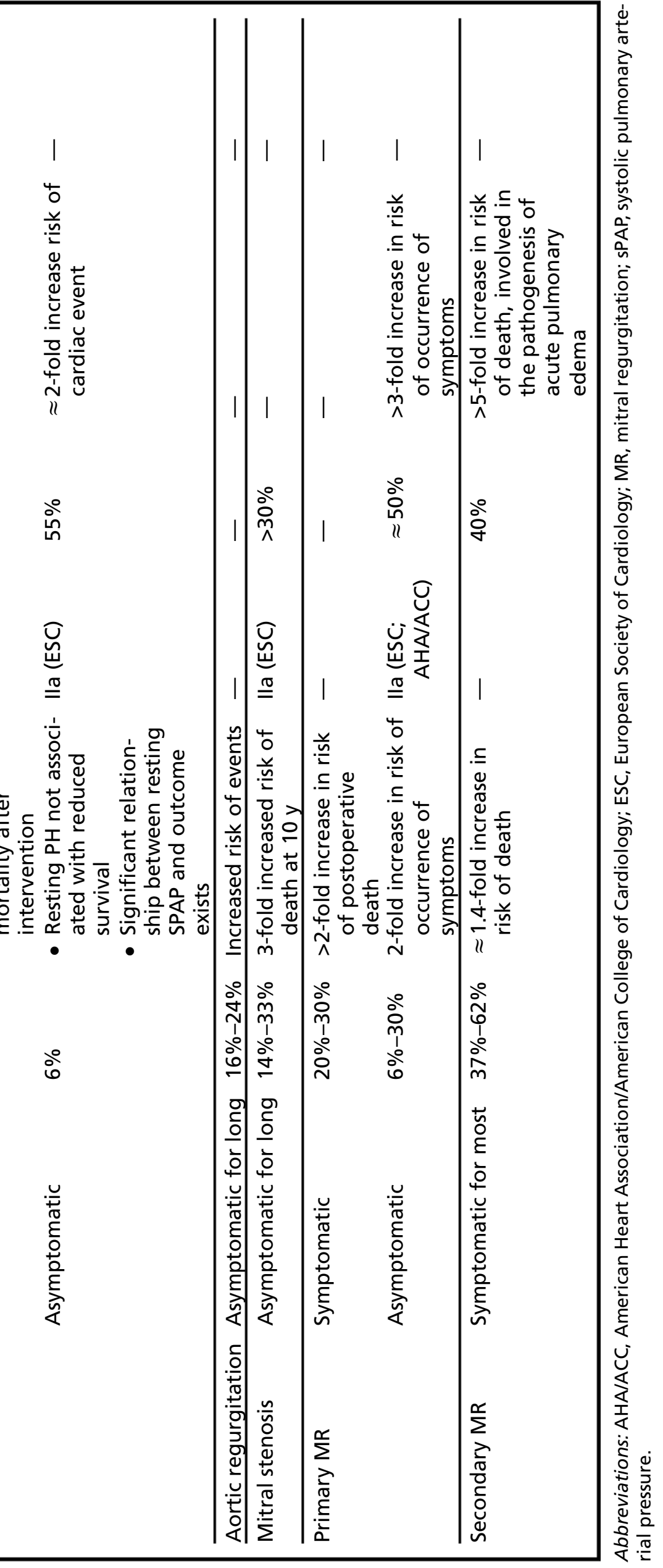


with New York Heart Association functional class III-IV. Greater than $40 \%$ of patients presenting with secondary MR and LV dysfunction experienced moderate-severe $\mathrm{PH} .{ }^{21,22}$ Resting $\mathrm{PH}$ may be also found in MR and preserved LV function. ${ }^{23}$

In cases of primary MR, it has been previously demonstrated that $\mathrm{PH}$ at baseline was a powerful predictor of poor outcomes in terms of survival, heart failure symptoms, LV function, and LV remodeling whatever initial LV function or clinical status. ${ }^{20,22,24,25}$ In patients with severe primary $\mathrm{MR}$ and preserved LV function, initial $\mathrm{PH}$ was associated with postoperative LV dysfunction (LV ejection fraction [LVEF] $<50 \%$ ). Barbieri and colleagues ${ }^{24}$ reported in a large study that $\mathrm{PH}$ was a strong independent predictive factor of allcause mortality, cardiovascular mortality, and heart failure in degenerative MR. Le Tourneau and colleagues ${ }^{26}$ found similar results and suggested that pre-existing $\mathrm{PH}$ doubled the risk of postoperative mortality or heart failure after adjustment for cofactors at 8 years of follow-up. Mentias and colleagues $^{27}$ showed a greater relationship between the level of pre-existing $\mathrm{PH}$ and reduced postoperative survival. Previous data supported that early surgery might be beneficial in patients with $\mathrm{PH}$ whatever LV function or clinical status. Resting PH (sPAP >50 mm Hg) has been considered as a determinant criterion to trigger mitral valve repair in patients presenting with primary severe MR and no LV dysfunction or dilatation according to international recommendations (class Ila indication). ${ }^{17}$

In cases of secondary MR, similar results have been found. Resting $\mathrm{PH}$ was an independent predictive factor of death and congestive heart failure..$^{22,28}$ Miller and colleagues ${ }^{22}$ reported a 30\% increase of mortality in patients with $\mathrm{PH}$ as compared with those without $\mathrm{PH}$, after adjustment for MR severity, clinical status, and LV systolic and diastolic function. Nevertheless, management of patients with secondary MR is still challenging in case of severe asymptomatic MR. ${ }^{2,17}$

\section{RESTING PULMONARY HYPERTENSION AND MITRAL STENOSIS}

The prevalence of $\mathrm{PH}$ in mitral stenosis (MS) is related to MS severity and clinical status and varies ranging from $14 \%$ to $33 \%$ for moderate $\mathrm{PH}$ and $5 \%$ to $9.6 \%$ for severe $\mathrm{PH} .{ }^{29,30} \mathrm{PH}$ is closely associated with heart failure symptoms and recent studies confirmed the prognostic value of $\mathrm{PH}$ in $\mathrm{MS}^{2,31}$ Yang and colleagues ${ }^{32}$ suggested that moderate and severe $\mathrm{PH}$ was associated with adverse outcomes in MS after adjustment of confounding factors. Similarly, Fawzy and colleagues $^{33}$ determined that severe $\mathrm{PH}$ (sPAP $>60 \mathrm{~mm} \mathrm{Hg}$ ) was associated with higher risk of cardiovascular events at midterm follow-up after percutaneous balloon. Patients presenting with $\mathrm{MS}$ and moderate-severe $\mathrm{PH}$ had a three-fold increased hazard ratio of death at 10 years compared with patients with normalmoderate PH (sPAP from 35 to $44 \mathrm{~mm} \mathrm{Hg}$ ). ${ }^{34}$ Death resulted in most from congestive heart failure, acute pulmonary edema, and RV heart failure. ${ }^{2} \mathrm{PH}$ is partially reversible after mitral valvular replacement. Parvathy and colleagues ${ }^{35}$ explained that not only did $\mathrm{PH}$ decrease after surgery but its regression was in concert with improvement of RV and LV remodeling (except LA enlargement) and reduction of pulmonary vascular resistance. Pathologic changes might take longer to resolve and differ in time and in degree from relative preoperative $\mathrm{PH}$.

There is no doubt that surgery or percutaneous balloon is recommended for symptomatic significant MS (valve area $\left.<1.5 \mathrm{~cm}^{2}\right) .{ }^{17}$ However, the role of resting $\mathrm{PH}$ in management of mild or asymptomatic MS differed according to European and American guidelines. The American guidelines propose to refer patients for surgery or percutaneous balloon before the progression of severe $\mathrm{PH},{ }^{36}$ whereas the European guidelines recommend to warrant an annual follow-up for patients presenting with symptomatic moderate MS (surface area $>1.5 \mathrm{~cm}^{2}$ and mean transmitral gradient $<5 \mathrm{~mm} \mathrm{Hg}$ ) and to perform percutaneous balloon in selective asymptomatic patients with high risk of decompensation. ${ }^{17}$

\section{RESTING PULMONARY HYPERTENSION AND AORTIC REGURGITATION}

Aortic regurgitation (AR) is defined by a diastolic reflux of blood from aorta to LV. PH appears at advanced stage in natural history of AR, because LV has the ability to adapt to pressure and volume overload. ${ }^{37}$ With time, LV volume increases and LV systolic function decreases with a decrease in LV diastolic compliance and an increase in LV filling pressure, which leads to increased sPAP.

The prevalence of $\mathrm{PH}$ in $\mathrm{AR}$ is, however, less documented. Severe PH (sPAP $>60 \mathrm{~mm} \mathrm{Hg}$ ) was reported in $16 \%$ to $24 \%$ of patients with severe chronic AR. ${ }^{38,39}$

The prognostic value of resting $\mathrm{PH}$ is not completely elucidated. In a recent retrospective study including 506 patients with severe AR, Khandhar and colleagues ${ }^{38}$ showed that severe $\mathrm{PH}$ was associated with LV dysfunction and functional MR and returned to normal in most cases after surgery. AVR was an independent predictor of 

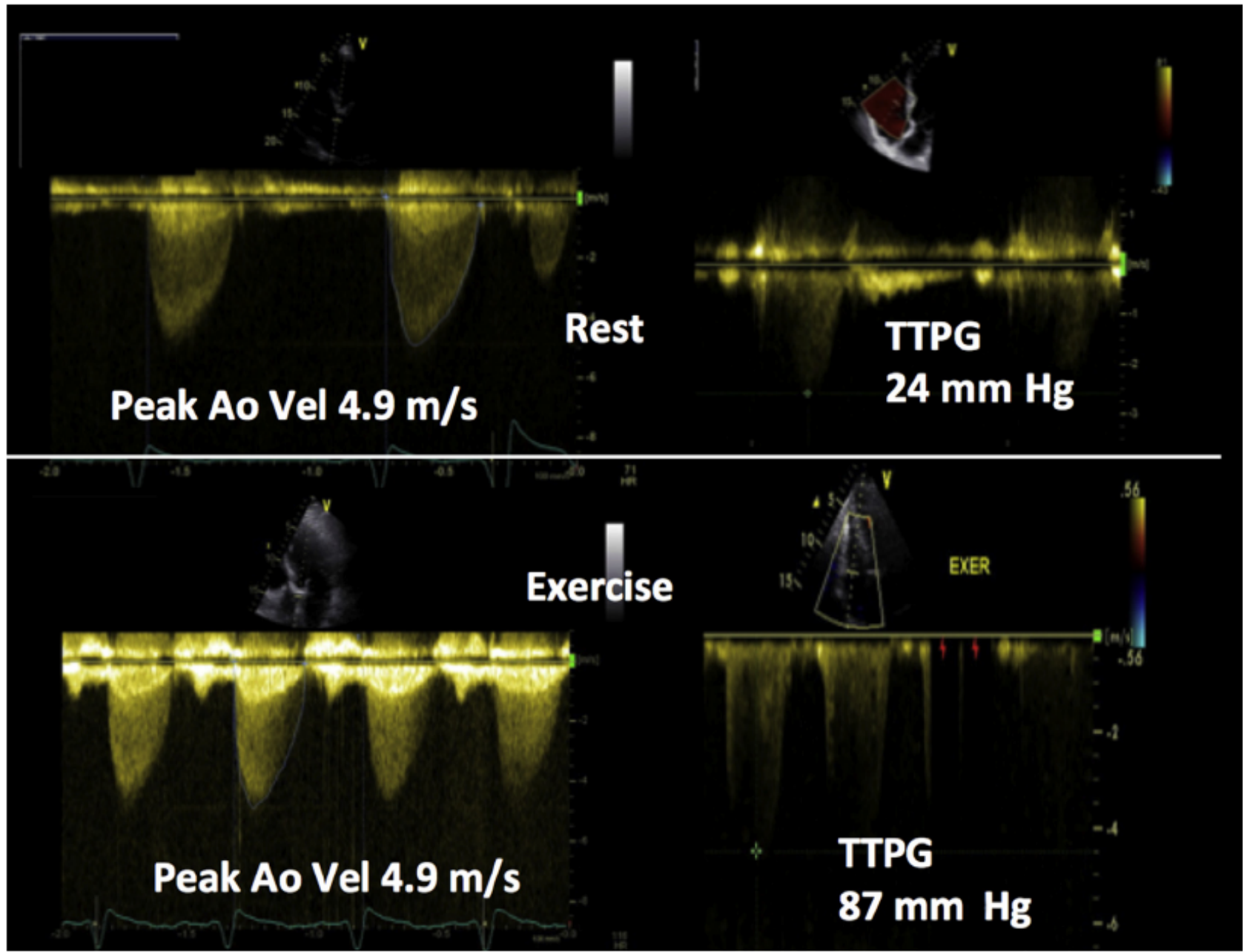

Fig. 2. Example of dynamic increase in systolic pulmonary arterial pressure during exercise in a patient with severe aortic stenosis (peak aortic jet velocity $>4 \mathrm{~m} / \mathrm{s}$ ). Ao Vel, aortic jet velocity; TTPG, transtricuspid pressure gradient.

better survival at 5 years follow-up in patients with both severe chronic AR and severe $\mathrm{PH}$. Consistently with previous data, Varadarajan and colleagues $^{40}$ described that $35 \%$ of patients with severe AR had TR greater than 2 . TR was related to sPAP (PH was present in $25 \%$ of patients with TR $>2$, whereas only $8 \%$ in patients with mild TR). AVR in this subgroup was associated with a better 5-year survival (78\% vs $42 \%$; $P<.001)$, despite higher $\mathrm{PH}$.

However, $\mathrm{PH}$ plays a modest role in the current management of AR according to recommendations. $\mathrm{PH}$ in AR should be considered as a marker of limited functional capacity, which might encourage clinicians to propose AVR. ${ }^{2}$

\section{EXERCISE PULMONARY HYPERTENSION AND VALVULAR HEART DISEASE}

Resting $\mathrm{PH}$ is common in severe and symptomatic VHD and more rarely reported in asymptomatic patients (Figs. 2 and 3). ${ }^{19}$ Nevertheless, patients can remain asymptomatic for a prolonged period of time at early stages of VHD and develop either exercise-related symptoms, such as dyspnea, before displaying heart failure. Symptoms at exercise are related to increased SPAP secondary to the increment of LV filling pressure in relation to advanced grade of diastolic dysfunction, severity of VHD, and RV function adaptation capacity and pulmonary vascular function. $^{2}$ Exercise echocardiography should therefore contribute to unmask patients with hidden symptoms, revealing moderate or severe VHD. It has been suggested that exercise echocardiography was a useful tool to screen exercise-induced $\mathrm{PH}(\mathrm{EIPH})$ and to identify patients with asymptomatic VHD at rest and higher risk of further worsening. ${ }^{25}$ Previous study also suggested that the kinetic of changes of exercise PAP were a marker of adverse outcomes in VHD rather than the level of exercise PAP. ${ }^{41}$

It was demonstrated that exercise echocardiography improved the risk stratification in asymptomatic AS with preserved LV function. ${ }^{42,43}$ Lancellotti and colleagues ${ }^{43}$ found that EIPH (sPAP >60 mm Hg) was present in 55\% of patients with severe AS and normal LVEF. After a 

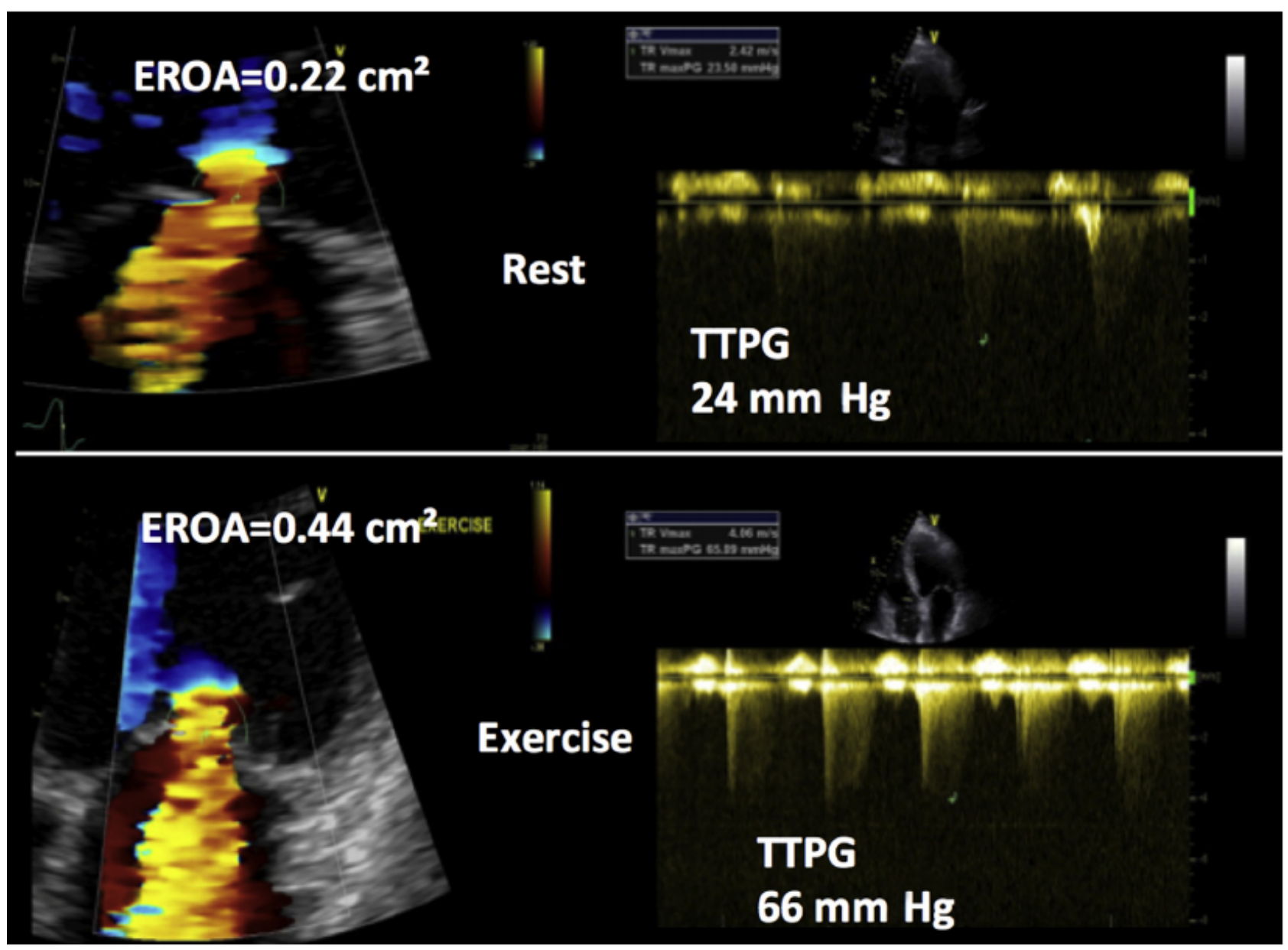

Fig. 3. Example of dynamic increase in systolic pulmonary arterial pressure and in mitral regurgitation severity during exercise in a patient with secondary mitral regurgitation and left ventricular systolic dysfunction. EROA, effective regurgitant orifice; TTPG, transtricuspid pressure gradient.

mean follow-up of $19 \pm 11$ months, EIPH was independently associated with a two-fold increase risk of cardiac events, even after adjustment with demographic data, resting $\mathrm{PH}$, and other exercise echocardiographic parameters. EIPH should help to individualize a subgroup of high-risk patients with asymptomatic AS. Surgery might be reasonable in case of increase greater than $20 \mathrm{~mm} \mathrm{Hg}$, whereas a closer follow-up should be warranted for patients without EIPH. ${ }^{2}$

EIPH was more frequent in asymptomatic patients with primary MR and preserved LV function and size, than resting $\mathrm{PH}$. Magne and colleagues ${ }^{44}$ described for the first time EIPH in 78 patients with moderate and severe primary MR. Only $20 \%$ of patient with EIPH did not develop symptoms after mean follow-up 19 months. A cutoff value of $56 \mathrm{~mm} \mathrm{Hg}$ for EIPH was the best predictor of symptoms. More recently, Kusunose and colleagues $^{45}$ suggested that the combination of EIPH (sPAP >54 $\mathrm{mm} \mathrm{Hg}$ ) and exercise-induced RV dysfunction (tricuspid annular plane systolic excursion (TAPSE) $<19 \mathrm{~mm}$ ) was a better predictor of worst outcome that EIPH alone in patients with asymptomatic degenerative MR. Exercise RV dysfunction should be taken into account with EIPH to predict outcomes in asymptomatic patients with primary MR. In addition, EIPH was a predictive factor of cardiac events after MV repair. To summarize, asymptomatic patients with primary moderate and severe MR and EIPH greater than $60 \mathrm{~mm} \mathrm{Hg}$ might be referred to surgery.

The prevalence of EIPH was estimated at $40 \%$ in patients with secondary MR whatever LV function. ${ }^{46}$ Dynamic MR and subsequent dynamic $\mathrm{PH}$ was a main predictive factor of worsening heart failure and mortality in patients with chronic LV dysfunction ${ }^{47}$ and the established cutoff value for the increase in SPAP is $21 \mathrm{~mm} \mathrm{Hg} .^{48}$ Surgery might be recommended in patients with EIPH, exerciseinduced MR, and planned coronary artery bypass. In the absence of surgical decision, a closer follow-up should be warranted.?

\section{RIGHT VENTRICULAR FUNCTION AND AORTIC STENOSIS}

There are limited data regarding the prevalence of RV dysfunction in AS. Galli and colleagues ${ }^{49}$ found RV dysfunction (assessed by TAPSE 
$<17 \mathrm{~mm}$ ) in 48 of 200 patients (24\%) presenting with severe AS. Similarly, Koifman and colleagues ${ }^{50}$ reported $24 \%$ of $\mathrm{RV}$ dysfunction in a larger study included 606 patients with severe AS undergoing TAVR.

Several mechanisms leading to RV dysfunction have been determined. As classically described in the VHD model, LV remodeling contributed to the increase of LV end-diastolic pressure and of PCWP and RV dysfunction resulted directly from increased SPAP at final stages. ${ }^{51}$ Indeed, Galli and colleagues ${ }^{49}$ demonstrated a main correlation between LV systolic function and RV performance, related to $\mathrm{RV}$-LV interdependence, whereas SPAP was not a determinant predictor of RV function. They suggested that the increase of sPAP noticed 1 year after AVR or TAVR might be the consequence of irreversible structural damage of RV function and morphology, because significantly RV dilatation at advanced RV failure exceeded adaptive stage. Before irreversible damage, RV function and size may improve after TAVR. ${ }^{50}$

Data on the impact of RV function on outcomes are limited. Galli and colleagues demonstrated that a biventricular dysfunction (LVEF $<50 \%$ and TAPSE $<17 \mathrm{~mm}$ ) was a main predictor of mortality in patients with severe AS independent of the strategy of treatment chosen (hazard ratio, 4.08 [1.36-12.22]; $P=.012$ ), whereas RV dysfunction alone was not a significant prognostic indicator. In patients with AS referred to surgical AVR, impaired RV function was a known adverse prognostic factor, ${ }^{8}$ whereas in patients with severe AS undergoing TAVR, Koifman and colleagues ${ }^{50}$ did not find a significant association between RV dysfunction (assessed by TAPSE <17, s' $<9.5 \mathrm{~cm} / \mathrm{s}$, and fractional area change $<0.35$ ) and mortality. In contrast, Testa and colleagues ${ }^{52}$ identified severe RV dilatation and dysfunction (TAPSE $<10 \mathrm{~mm}$ ) as independent predictors of 1-year mortality in a larger study including patients with severe AS undergoing TAVR. Several investigations emphasized the prognostic value of RV dilatation in patients with severe AS undergoing TAVR ${ }^{53,54}$ In addition, in patients with low flow/low gradient AS, RV function has been considered as marker of poor prognosis and should be take into account in the decisionmaking process. ${ }^{55}$

Nevertheless, whatever the method of assessment of RV function (quantitative, semiquantitative, or qualitative), RV dysfunction should be considered as a marker of poor prognosis in advanced VHD. The prognostic value and the implication of $\mathrm{RV}$ in the strategy management require further investigation.

\section{RIGHT VENTRICULAR FUNCTION AND MITRAL REGURGITATION}

RV impairment has been commonly observed in MR with or without LV dysfunction, in particular in patients with large regurgitation. ${ }^{56}$ Le Tourneau and colleagues ${ }^{57}$ reported a prevalence of $30 \%$ of $\mathrm{RV}$ dysfunction in patients with severe organic MR referred to surgery. In a small study including 60 patients with high-risk functional MR undergoing MitraClip, moderate and severe RV dysfunction (TAPSE $<16 \mathrm{~mm}$ and $\mathrm{S}^{\prime}<10 \mathrm{~cm} / \mathrm{s}$ ) was noticed in $37 \%$ of cases. ${ }^{58}$

RV dysfunction results from complex hemodynamic and structural changes. Downstream, chronic MR leads to LV volume overload with subsequent LV enlargement and a decrease of interventricular septal function, and upstream, induces an increase in LA pressure and with a subsequent increase in SPAP and PCWP. ${ }^{5}$ It is speculated that RV dysfunction may be the consequence of RV pressure afterload. Nevertheless, several observations demonstrated that LV remodeling and septal function were the main determinant of RV function impairment, rather than $\mathrm{PH} .{ }^{57}$

There are conflicting results regarding the prognostic value of RV function in functional MR. Isolated RV dysfunction has not been considered as a predictive factor of early and long-term mortality after surgery, ${ }^{59,60}$ whereas biventricular dysfunction (LVEF $<60 \%$ and right ventricular ejection fraction $<35 \%$ ) was associated with mid- and longterm poor outcome in patients with severe organic MR. ${ }^{57}$ In a recent study including 117 patients with severe functional MR undergoing MitraClip, Kaneko and colleagues ${ }^{61}$ demonstrated that preexisting RV dysfunction (TAPSE $<16 \mathrm{~mm}$ ) was significantly associated with all-cause mortality at 6 months follow-up despite a similar improvement of $\mathrm{MR}$ regardless of $\mathrm{RV}$ function (hazard ratio, 1.975 [1.026-3.805]; $P=.042$ ). Conversely, Godino and colleagues ${ }^{58}$ reported that successful MitraClip procedure leads to a significant improvement of RV function even in patients with baseline RV dysfunction (TAPSE $<16 \mathrm{~mm}$ and/or S' $<10 \mathrm{~cm} / \mathrm{s}$ ). Reverse RV remodeling and reduced RV pressure overload by regression of MR and SPAP might explain its functional benefit. However, patients with baseline RV dysfunction presented more frequently with adverse events (stroke and heart failure) as compared with patients without RV dysfunction, as demonstrated by Neuss and colleagues. ${ }^{62}$ Moreover, data are lacking regarding the prognostic value of RV dysfunction and longterm effects of persistent MR after valvulopathy correction on RV size and function. ${ }^{63}$ Previous data showed that RV assessment should be useful 
to improve management process but further investigations are required.

\section{RIGHT VENTRICULAR FUNCTION AND MITRAL STENOSIS}

RV function is frequently impaired in MS and remains an essential step in the development of clinical symptoms and in progression of the disease. $^{64,65} \mathrm{RV}$ dysfunction may be attributed to two different mechanisms. First, RV impairment resulted from RV increased afterload and $\mathrm{PH}$, caused by increased LA pressure and chronic pulmonary congestion. ${ }^{7}$ Second, prior studies suggested that RV dysfunction was related to rheumatic involvement with subsequent myocyte necrosis, replacement by fibrosis, and calcification. ${ }^{66,67}$ Nevertheless, $\mathrm{PH}$ seemed to be a determinant of RV impairment because changes in RV function depended on the degree of $\mathrm{PH} .{ }^{68}$

Several studies demonstrated that RV function improved in the early period and the improvement seemed to continue at the late period after postoperative MS correction. Kumar and colleagues ${ }^{69}$ analyzed RV strain and strain rate in 60 patients with severe MS before and after valvulopathy correction. They showed a significant increase in peak systolic global and segmental RV strain at basal, mid, and distal septum. There was no change in strain rate, because strain rate did not depend on load. They reported also a significant increase of TAPSE and RV fractional area change, whereas Tei index, s', and Isolumic acceleration were not affected by percutaneous valvuloplasty. On the contrary, Drighil and colleagues ${ }^{70}$ suggested that Tei index and Fractional Area Change (FAC) improved immediately after Percutaneous balloon mitral valvuloplasty (PBMV) in 12 patients presenting with MS. These discordant results may be explained by the parameters used for RV function evaluation, which depended or not on load condition. ${ }^{69}$ Nevertheless, it has been proved that the release of mitral valve obstruction by PBMV in patients in sinus rhythm led to decreased LA volume, which contributed to reduce chronic pulmonary congestion, $\mathrm{PH}$, and $\mathrm{RV}$ afterload. ${ }^{71}$ Pre-existing RV dysfunction did not prevent clinical improvement after PBMV. ${ }^{72}$ Further investigations with larger populations are required to assess $\mathrm{RV}$ remodeling and long-term outcomes of patients with MS after percutaneous valvuloplasty.

\section{RIGHT VENTRICULAR FUNCTION AND AORTIC REGURGITATION}

Data are limited concerning RV impairment in AR. A study analyzed the consequences of LV volume overload in 40 patients with severe AR on RV diastolic function. Patients with elevated RV pressure (>30 mm Hg) were excluded. RV diastolic function was assessed by echocardiography, based on Doppler-derived indexes and RV isovolumic relaxation time. Dourvas and colleagues ${ }^{73}$ found abnormal relaxation and RV filling along diastole related in case of severe $A R$ and suggested that $\mathrm{RV}$ diastolic impairment was related to LV dilatation and ventricular interdependence. To the best our knowledge, the prognostic value of RV dysfunction in severe AR has not yet been studied.

\section{SUMMARY}

VHD is the most frequent cause of $\mathrm{PH}$. Regardless of VHD type, resting $\mathrm{PH}$ is closely linked with clinical symptoms and poor prognosis. Even though resting $\mathrm{PH}$ remains a classic indication of VHD correction, a more aggressive approach might be proposed for selected patients with normal resting PAP but abnormal increase during exercise. Finally, because the left and right side of heart and lung vasculature formed a global unit, PAP, LV, and RV function are closely linked and should be considered and evaluated as a whole unit.

\section{REFERENCES}

1. Fang JC, DeMarco T, Givertz MM, et al. World Health Organization pulmonary hypertension group 2: pulmonary hypertension due to left heart disease in the adult. A summary statement from the Pulmonary Hypertension Council of the International Society for Heart and Lung Transplantation. J Heart Lung Transplant 2012;31(9):913-33.

2. Magne J, Pibarot P, Sengupta PP, et al. Pulmonary hypertension in valvular disease: a comprehensive review on pathophysiology to therapy from the HAVEC Group. JACC Cardiovasc Imaging 2015; 8(1):83-99.

3. Cooper CJ, Jevnikar FW, Walsh T, et al. The influence of basal nitric oxide activity on pulmonary vascular resistance in patients with congestive heart failure. Am J Cardiol 1998;82(5):609-14.

4. Rudski LG, Lai WW, Afilalo J, et al. Guidelines for the echocardiographic assessment of the right heart in adults: a report from the American Society of Echocardiography endorsed by the European Association of Echocardiography, a registered branch of the European Society of Cardiology, and the Canadian Society of Echocardiography. J Am Soc Echocardiogr 2010;23(7):685-713 [quiz: 786-8].

5. le Tourneau T. Right ventricle impairment: are we changing the paradigm in organic mitral regurgitation? Arch Cardiovasc Dis 2013;106(8-9):419-22. 
6. Badano LP, Ginghina C, Easaw J, et al. Right ventricle in pulmonary arterial hypertension: haemodynamics, structural changes, imaging, and proposal of a study protocol aimed to assess remodelling and treatment effects. Eur J Echocardiogr 2010;11(1):27-37.

7. Nagel E, Stuber M, Hess OM. Importance of the right ventricle in valvular heart disease. Eur Heart J 1996;17(6):829-36.

8. Kammerlander AA, Marzluf BA, Graf A, et al. Right ventricular dysfunction, but not tricuspid regurgitation, is associated with outcome late after left heart valve procedure. J Am Coll Cardiol 2014;64(24): 2633-42.

9. Lancellotti P, Magne J, Donal E, et al. Determinants and prognostic significance of exercise pulmonary hypertension in asymptomatic severe aortic stenosis. Circulation 2012;126(7):851-9.

10. Faggiano P, Antonini-Canterin F, Ribichini F, et al. Pulmonary artery hypertension in adult patients with symptomatic valvular aortic stenosis. Am J Cardiol 2000;85(2):204-8.

11. Melby SJ, Moon MR, Lindman BR, et al. Impact of pulmonary hypertension on outcomes after aortic valve replacement for aortic valve stenosis. J Thorac Cardiovasc Surg 2011;141(6):1424-30.

12. Roselli EE, Abdel Azim A, Houghtaling PL, et al. Pulmonary hypertension is associated with worse early and late outcomes after aortic valve replacement: implications for transcatheter aortic valve replacement. J Thorac Cardiovasc Surg 2012;144(5): 1067-74.e2.

13. Malouf JF, Enriquez-Sarano M, Pellikka PA, et al. Severe pulmonary hypertension in patients with severe aortic valve stenosis: clinical profile and prognostic implications. J Am Coll Cardiol 2002;40(4):789-95.

14. Pai RG, Varadarajan P, Kapoor N, et al. Aortic valve replacement improves survival in severe aortic stenosis associated with severe pulmonary hypertension. Ann Thorac Surg 2007;84(1):80-5.

15. Zuern CS, Eick C, Rizas K, et al. Prognostic value of mild-to-moderate pulmonary hypertension in patients with severe aortic valve stenosis undergoing aortic valve replacement. Clin Res Cardiol 2012; 101(2):81-8.

16. Barbash IM, Escarcega RO, Minha S, et al. Prevalence and impact of pulmonary hypertension on patients with aortic stenosis who underwent transcatheter aortic valve replacement. Am J Cardiol 2015;115(10):1435-42.

17. Baumgartner H, Falk V, Bax JJ, et al. 2017 ESC/ EACTS guidelines for the management of valvular heart disease: the task force for the management of valvular heart disease of the European Society of Cardiology (ESC) and the European Association for Cardio-Thoracic Surgery (EACTS). Eur Heart J 2017;38(36):2739-91.
18. Nishimura RA, Otto CM, Bonow RO, et al. 2017 AHA/ ACC focused update of the 2014 AHA/ACC guideline for the management of patients with valvular heart disease: a report of the American College of Cardiology/American Heart Association Task Force on Clinical Practice Guidelines. J Am Coll Cardiol 2017;70(2):252-89.

19. Martinez C, Bernard A, Dulgheru R, et al. Pulmonary hypertension in aortic stenosis and mitral regurgitation: rest and exercise echocardiography significance. Prog Cardiovasc Dis 2016; 59(1):59-70.

20. Ghoreishi M, Evans CF, DeFilippi CR, et al. Pulmonary hypertension adversely affects short- and long-term survival after mitral valve operation for mitral regurgitation: implications for timing of surgery. J Thorac Cardiovasc Surg 2011;142(6): 1439-52.

21. Kainuma S, Taniguchi K, Toda K, et al. Pulmonary hypertension predicts adverse cardiac events after restrictive mitral annuloplasty for severe functional mitral regurgitation. J Thorac Cardiovasc Surg 2011;142(4):783-92.

22. Miller WL, Mahoney DW, Enriquez-Sarano M. Quantitative Doppler-echocardiographic imaging and clinical outcomes with left ventricular systolic dysfunction: independent effect of pulmonary hypertension. Circ Cardiovasc Imaging 2014;7(2):330-6.

23. Maréchaux S, Neicu DV, Braun S, et al. Functional mitral regurgitation: a link to pulmonary hypertension in heart failure with preserved ejection fraction. J Card Fail 2011;17(10):806-12.

24. Barbieri A, Bursi F, Grigioni F, et al. Prognostic and therapeutic implications of pulmonary hypertension complicating degenerative mitral regurgitation due to flail leaflet: a multicenter long-term international study. Eur Heart J 2011;32(6):751-9.

25. Magne J, Lancellotti P, Piérard LA. Exercise pulmonary hypertension in asymptomatic degenerative mitral regurgitation. Circulation 2010;122(1):33-41.

26. Le Tourneau T, Richardson M, Juthier F, et al. Echocardiography predictors and prognostic value of pulmonary artery systolic pressure in chronic organic mitral regurgitation. Heart 2010;96:1311-7.

27. Mentias A, Patel K, Patel H, et al. Effect of pulmonary vascular pressures on long-term outcome in patients with primary mitral regurgitation. J Am Coll Cardiol 2016;67(25):2952-61.

28. Agricola E, Stella S, Gullace M, et al. Impact of functional tricuspid regurgitation on heart failure and death in patients with functional mitral regurgitation and left ventricular dysfunction. Eur $J$ Heart Fail 2012;14(8):902-8.

29. Kim H-K, Kim Y-J, Hwang S-J, et al. Hemodynamic and prognostic implications of net atrioventricular compliance in patients with mitral stenosis. J Am Soc Echocardiogr 2008;21(5):482-6. 
30. Fawzy ME, Hassan W, Stefadouros M, et al. Prevalence and fate of severe pulmonary hypertension in 559 consecutive patients with severe rheumatic mitral stenosis undergoing mitral balloon valvotomy. J Heart Valve Dis 2004;13(6):942-7 [discussion: 947-8].

31. Maoqin S, Guoxiang H, Zhiyuan S, et al. The clinical and hemodynamic results of mitral balloon valvuloplasty for patients with mitral stenosis complicated by severe pulmonary hypertension. Eur J Intern Med 2005;16(6):413-8.

32. Yang H, Davidson WR Jr, Chambers CE, et al. Preoperative pulmonary hypertension is associated with postoperative left ventricular dysfunction in chronic organic mitral regurgitation: an echocardiographic and hemodynamic study. J Am Soc Echocardiogr 2006;19:1051-5.

33. Fawzy ME, Osman A, Nambiar V, et al. Immediate and long-term results of mitral balloon valvuloplasty in patients with severe pulmonary hypertension. J Heart Valve Dis 2008;17(5):485-91.

34. Yang B, DeBenedictus C, Watt T, et al. The impact of concomitant pulmonary hypertension on early and late outcomes following surgery for mitral stenosis. J Thorac Cardiovasc Surg 2016;152(2): 394-400.e1.

35. Parvathy UT, Rajan R, Faybushevich AG. Reversal of abnormal cardiac parameters following mitral valve replacement for severe mitral stenosis in relation to pulmonary artery pressure: a retrospective study of noninvasive parameters - Early and late pattern. Interv Med Appl Sci 2016;8(2):49-59.

36. Nishimura RA, Otto CM, Bonow RO, et al. 2014 AHA/ ACC guideline for the management of patients with valvular heart disease: a report of the American College of Cardiology/American Heart Association task force on practice guidelines. J Thorac Cardiovasc Surg 2014;148(1):e1-132.

37. Bekeredjian R, Grayburn PA. Valvular heart disease: aortic regurgitation. Circulation 2005;112(1): 125-34.

38. Khandhar S, Varadarajan P, Turk R, et al. Survival benefit of aortic valve replacement in patients with severe aortic regurgitation and pulmonary hypertension. Ann Thorac Surg 2009;88(3):752-6.

39. Naidoo DP, Mitha AS, Vythilingum S, et al. Pulmonary hypertension in aortic regurgitation: early surgical outcome. Q J Med 1991;80(291):589-95.

40. Varadarajan P, Patel R, Turk R, et al. Etiology impacts survival in patients with severe aortic regurgitation: results from a cohort of 756 patients. J Heart Valve Dis 2013;22(1):42-9.

41. Lewis GD, Murphy RM, Shah RV, et al. Pulmonary vascular response patterns during exercise in left ventricular systolic dysfunction predict exercise capacity and outcomes. Circ Heart Fail 2011;4(3): 276-85.
42. Maréchaux S, Hachicha Z, Bellouin A, et al. Usefulness of exercise-stress echocardiography for risk stratification of true asymptomatic patients with aortic valve stenosis. Eur Heart J 2010;31(11): 1390-7.

43. Lancellotti P, Lebois F, Simon M, et al. Prognostic importance of quantitative exercise Doppler echocardiography in asymptomatic valvular aortic stenosis. Circulation 2005;112(9 Suppl):I377-82.

44. Magne J, Donal E, Mahjoub H, et al. Impact of exercise pulmonary hypertension on postoperative outcome in primary mitral regurgitation. Heart 2015;101(5):391-6.

45. Kusunose K, Popović ZB, Motoki H, et al. Prognostic significance of exercise-induced right ventricular dysfunction in asymptomatic degenerative mitral regurgitation. Circ Cardiovasc Imaging 2013;6(2): 167-76.

46. Lancellotti P, Magne J, Dulgheru R, et al. Clinical significance of exercise pulmonary hypertension in secondary mitral regurgitation. Am J Cardiol 2015; 115(10):1454-61.

47. Lancellotti P, Gérard PL, Piérard LA. Long-term outcome of patients with heart failure and dynamic functional mitral regurgitation. Eur Heart J 2005; 26(15): 1528-32.

48. Piérard LA, Lancellotti P. The role of ischemic mitral regurgitation in the pathogenesis of acute pulmonary edema. N Engl J Med 2004;351(16):1627-34.

49. Galli E, Guirette Y, Feneon D, et al. Prevalence and prognostic value of right ventricular dysfunction in severe aortic stenosis. Eur Heart J Cardiovasc Imaging 2015;16(5):531-8.

50. Koifman E, Didier R, Patel N, et al. Impact of right ventricular function on outcome of severe aortic stenosis patients undergoing transcatheter aortic valve replacement. Am Heart J 2017;184:141-7.

51. Vachiéry J-L, Adir Y, Barberà JA, et al. Pulmonary hypertension due to left heart diseases. Turk Kardiyol Dern Ars 2014;42(Suppl 1):130-41 [in Turkish].

52. Testa L, Latib A, De Marco F, et al. The failing right heart: implications and evolution in high-risk patients undergoing transcatheter aortic valve implantation. Eurolntervention 2016;12(12):1542-9.

53. Ito S, Pislaru SV, Soo WM, et al. Impact of right ventricular size and function on survival following transcatheter aortic valve replacement. Int J Cardiol 2016;221:269-74.

54. Lindman BR, Maniar HS, Jaber WA, et al. Effect of tricuspid regurgitation and the right heart on survival after transcatheter aortic valve replacement: insights from the placement of aortic transcatheter valves II inoperable cohort. Circ Cardiovasc Interv 2015; 8(4) [pii:e002073].

55. Cavalcante JL, Rijal S, Althouse AD, et al. Right ventricular function and prognosis in patients with low- 


\section{Filippetti et al}

flow, low-gradient severe aortic stenosis. J Am Soc Echocardiogr 2016;29(4):325-33.

56. Le Tourneau T, de Groote P, Millaire A, et al. Effect of mitral valve surgery on exercise capacity, ventricular ejection fraction and neurohormonal activation in patients with severe mitral regurgitation. J Am Coll Cardiol 2000;36(7):2263-9.

57. Le Tourneau T, Deswarte G, Lamblin N, et al. Right ventricular systolic function in organic mitral regurgitation: impact of biventricular impairment. Circulation 2013;127(15):1597-608.

58. Godino C, Salerno A, Cera M, et al. Impact and evolution of right ventricular dysfunction after successful MitraClip implantation in patients with functional mitral regurgitation. Int J Cardiol Heart Vasc 2016; 11:90-8.

59. Corciova FC, Corciova C, Georgescu CA, et al. Echocardiographic predictors of adverse shortterm outcomes after heart surgery in patients with mitral regurgitation and pulmonary hypertension. Heart Surg Forum 2012;15(3):E127-32.

60. Sun X, Ellis J, Kanda L, et al. The role of right ventricular function in mitral valve surgery. Heart Surg Forum 2013;16(3):E170-6.

61. Kaneko H, Neuss M, Weissenborn J, Butter C. Prognostic Significance of Right Ventricular Dysfunction in Patients With Functional Mitral Regurgitation Undergoing MitraClip. Am J Cardiol 2016 Dec 1; 118(11):1717-22.

62. Neuss M, Schau T, Schoepp M, et al. Patient selection criteria and midterm clinical outcome for MitraClip therapy in patients with severe mitral regurgitation and severe congestive heart failure. Eur J Heart Fail 2013;15(7):786-95.

63. De Bonis M, Alfieri O. MitraClip and right ventricular function: hopes and doubts. Eur Heart J Cardiovasc Imaging 2014;15(1):104-5.

64. Sagie A, Freitas N, Padial LR, et al. Doppler echocardiographic assessment of long-term progression of mitral stenosis in 103 patients: valve area and right heart disease. J Am Coll Cardiol 1996;28(2): 472-9.
65. Mohan JC, Sengupta PP, Arora R. Immediate and delayed effects of successful percutaneous transvenous mitral commissurotomy on global right ventricular function in patients with isolated mitral stenosis. Int J Cardiol 1999;68(2):217-23.

66. Burger W, Illert S, Teupe C, et al. Right ventricular function in patients with rheumatic mitral valve stenosis. Effect of balloon mitral valvuloplasty. Z Kardiol 1993;82(9):545-51 [in German].

67. Harvey RM, Ferrer I, Samet P, et al. Mechanical and myocardial factors in rheumatic heart disease with mitral stenosis. Circulation 1955;11(4):531-51.

68. Mahfouz RA. Impact of pulmonary artery stiffness on right ventricular function and tricuspid regurgitation after successful percutaneous balloon mitral valvuloplasty: the importance of early intervention. Echocardiography 2012;29(10):1157-63.

69. Kumar V, Jose VJ, Pati PK, et al. Assessment of right ventricular strain and strain rate in patients with severe mitral stenosis before and after balloon mitral valvuloplasty. Indian Heart J 2014;66(2):176-82.

70. Drighil A, Bennis A, Mathewson JW, et al. Immediate impact of successful percutaneous mitral valve commissurotomy on right ventricular function. Eur J Echocardiogr 2008;9(4):536-41.

71. Adavane S, Santhosh S, Karthikeyan S, et al. Decrease in left atrium volume after successful balloon mitral valvuloplasty: an echocardiographic and hemodynamic study. Echocardiogr Mt Kisco N 2011;28(2):154-60.

72. Tigen K, Pala S, Sadic BO, et al. Effect of increased severity of mitral regurgitation and preprocedural right ventricular systolic dysfunction on biventricular and left atrial mechanical functions following percutaneous mitral balloon valvuloplasty. Echocardiogr Mt Kisco N 2014;31(10):1213-20.

73. Dourvas IN, Parharidis GE, Efthimiadis GK, et al. Right ventricular diastolic function in patients with chronic aortic regurgitation. Am J Cardiol 2004; 93(1):115-7. 
